\title{
A comprehensive narrative review of residual curvature correction during penile prosthesis implantation in patients with severe erectile dysfunction and concomitant Peyronie's disease
}

\author{
Ioannis Sokolakis ${ }^{1}$, Nikolaos Pyrgidis ${ }^{2}$, Ioannis Mykoniatis ${ }^{2}$, Fotios Dimitriadis ${ }^{2}$, \\ Georgios Hatzichristodoulou'
}

${ }^{1}$ Department of Urology, Martha-Maria Hospital Nuremberg, Nuremberg, Germany; ${ }^{2} 1^{\text {st }}$ Department of Urology, Aristotle University of Thessaloniki, Gennimatas Hospital, Thessaloniki, Greece

Contributions: (I) Conception and design: G Hatzichristodoulou, I Sokolakis; (II) Administrative support: G Hatzichristodoulou, F Dimitriadis; (III) Provision of study materials or patients: I Sokolakis, I Mykoniatis, N Pyrgidis; (IV) Collection and assembly of data: I Sokolakis, I Mykoniatis, N Pyrgidis; (V) Data analysis and interpretation: All authors; (VI) Manuscript writing: All authors; (VII) Final approval of manuscript: All authors.

Correspondence to: Ass. Prof. Dr. Georgios Hatzichristodoulou MD, PhD, FEBU, FECSM. Chief of Urology Department, Department of Urology, Martha-Maria Hospital Nuremberg, Stadenstr. 58, 90491 Nuremberg, Germany. Email: georgios.hatzichristodoulou@martha-maria.de.

\begin{abstract}
Residual curvature correction during penile prosthesis implantation (PPI) is usually needed in patients with severe erectile dysfunction (ED) and concomitant Peyronie's disease (PD). The aim of the study was to assess the different existing techniques for treating residual penile curvature during PPI in patients with severe PD and ED. We generated a comprehensive narrative review of the literature until August 2020 on the use of PPI in combination with straightening reconstruction techniques, in treating patients with severe PD and ED. We included studies published in English, assessing the PPI as primary intervention in patients with PD and ED. Secondary research studies and studies with insufficient data were excluded from final analyses. We included a total of 33 clinical articles with 1,612 patients that assessed the effects of PPI combined with straightening surgical techniques for the treatment of severe PD and ED. Based on the severity of penile curvature, the concomitance of additional penile deformities (i.e., hourglass deformity), the penile length, the presence of previous penile operations and the surgeon's experience, four main categories of surgical techniques were identified: (I) PPI with plication of the penis on the convex side of the curvature, (II) transcorporeal plaque incision/excision, (III) PPI with plaque/tunical incision(s) on the concave side of the curvature and (IV) PPI with plaque incision/excision plus grafting. Patients with severe PD and ED can expect excellent outcomes with PPI and surgical correction of residual penile curvature and minimal side effects. Overall, all the above techniques seem to able to correct the residual penile curvature during prosthesis implantation. Grafting techniques seem to be favorable in patients with additional severe penile shortening. Still, no definite conclusions can be drawn regarding the superiority of one technique over the other.
\end{abstract}

Keywords: Penile prosthesis; Peyronie's disease (PD); erectile dysfunction (ED), reconstructive surgery

Submitted Sep 05, 2020. Accepted for publication Nov 06, 2020.

doi: $10.21037 /$ tau-20-1236

View this article at: http://dx.doi.org/10.21037/tau-20-1236

\section{Introduction}

Implantation of an inflatable penile prosthesis is considered the gold standard therapy in patients with erectile dysfunction (ED) non-responsive to medical and conservative treatment with phosphodiesterase type5 inhibitors or intracavernosal injections of vasoactive agents (1). Penile prosthesis implantation (PPI) is also a treatment option in patients with Peyronie's disease (PD) 
and concomitant ED (2). Therefore, PPI, performed with or without adjunct straightening techniques, is considered a surgical option in PD patients with ED not responding to conventional medical therapy and concomitant penile curvature (3).

The choice of the best surgical option is essentially based on specific factors, comprising the penile length, the curvature severity and the erectile function status $(4,5)$. In patients with ED and severe penile curvature, the curvature may persist even after PPI in the cavernous bodies due to extensive plaque formation (6). To date, no certain evidence about the superiority of inflatable versus malleable prosthesis exists. Still, there are indications on whether or not to perform straightening techniques according to the degree of residual penile curvature after PPI.

In patients with $\mathrm{ED}$ and penile curvature $<30^{\circ}$, PPI alone or in combination with mild adjunctive maneuvers (e.g., modeling maneuver) can adequately correct, in most cases, the residual curvature (7). In this context, the penile implant acts as an internal tissue expander to correct the curvature over time (8). However, adjunctive maneuvers can lead to urethral injury, which renders necessary the removal of the implant and the abandonment of the surgical procedure (9). Nevertheless, the time-honored modeling is still considered the gold standard due to ease and effectiveness. The originally published drawbacks to the modeling technique of urethral injury and inadequate immediate straightening have been addressed by subsequent data from other studies (10). The urethra can be protected during modeling by Perito's "chicken choke". The disappointment of the patient on the morning after surgery that his penis is still a bit askew can be mitigated by repetitive modeling at surgery. Additionally, modeling of the crooked penis after PPI is not obsolete as an adjunctive procedure (11). Recently it is showed that optimal modeling could be both safe and effective in cases of moderate-severe penile curvature, precluding the need for more time-consuming and complex surgical procedures (12).

On the other hand, if the residual curvature is $>30^{\circ}$, the possibility of adding a straightening technique, such as plication, complex remodelling techniques, the execution of simple relaxing incisions or grafting techniques, should be considered (13). Within this framework, several authors have tried to suggest an algorithm to intraoperatively address residual penile curvature during PPI. Levine et al. recently presented the results of an algorithm to correct penile curvature during penile implantation. The authors suggested to initially perform manual modeling, followed by tunica incision for insufficient straightening $\left(>30^{\circ}\right.$ of residual curvature). For tunical defects greater than $2 \mathrm{~cm}$, patch grafting was performed to prevent prosthesis cylinder herniation and recurrent deformity from cicatrix contraction (14). A similar algorithm is also proposed from Mulhall et al. (15).

We aimed to extensively review the literature on the additional surgical straightening techniques beyond modeling to correct the residual curvature during PPI in patients with severe ED and concomitant PD. We present the following article in accordance with the Narrative Review Reporting Checklist. Available at: http://dx.doi. org/10.21037/tau-20-1236.

\section{Methods}

We comprehensively searched Medline and Cochrane Library databases from inception to August 2020. We applied the keywords "penile prosthesis" OR "penile implant(s)" in combination with (AND) "Peyronie('s)" OR "penile curvature" OR "induratio penis plastica". Additionally, the reference lists of all eligible studies and relevant reviews were hand-searched to identify additional records. Furthermore, we perused articles that were suggested by the "related citations" option of PubMed.

We included studies published in English assessing the PPI as primary intervention in patients with PD and ED and including a surgical reconstructive straightening technique. We excluded articles involving simple PPI with or without manual modeling for the correction of residual penile curvature. We further excluded articles involving reconstructive lengthening techniques when no additional penile curvature was present. We excluded articles that did not provide sufficient information about the surgical treatment or the pre- and postoperative evaluation. Animal studies, conference abstracts, case reports and secondary research studies were also excluded.

After screening titles and abstracts of all retrieved studies, articles assessing the PPI in combination with additional surgical reconstructive straightening techniques in patients with ED and penile curvature were evaluated as full-texts. The assessment of full-texts was conducted by three reviewers (IS, NP, and IM) independently according to our predefined selection criteria. Data extraction was performed in a predefined Microsoft Excel spreadsheet. Penile straightening along with patient's satisfaction were the two primary outcomes of this review. Additional important secondary outcomes were postoperative penile length, short- and long-term complications, as well as 
device malfunction. Any discrepancies among the reviewers were resolved by consensus.

\section{Evidence synthesis}

We included a total of 33 studies with 1,612 participants that investigated the additional surgical straightening techniques to correct the residual curvature during PPI in patients with severe ED and concomitant PD. There is an increasing scientific interest regarding these techniques. Only 11 articles were published until 2010 (14,16-25). Most of the articles were published during the last decade (26-47). Most studies had a retrospective design and only five studies were prospective $(17,20,30,41,43)$. Four of them were single-arm and one was a non-randomized comparative study, assessing two grafting materials for the penile straightening after PPI.

Based on the severity of the penile curvature, the concomitance of additional penile deformities (i.e., hourglass deformity), the penile length, the presence of previous penile operations and the surgeon's experience, four main categories of surgical reconstructive straightening techniques for residual penile curvature during PPI were identified: (I) PPI with plication of the penis on the convex side of the curvature, (II) PPI with transcavernosal plaque incision/excision, (III) PPI with relaxing plaque/tunical incision(s) on the concave side of the curvature, and (IV) PPI with plaque/tunical incision/excision plus grafting. The grafting category was further classified into the following techniques: simple plaque incision/excision plus grafting of the tunical defect, circumferential tunical incision plus grafting, sliding technique with grafting and modifications or combinations of the above.

\section{Plication techniques}

A total of 5 studies with 69 patients investigated the PPI in combination with a plication technique for the correction of residual curvature (Table 1) (16,26-29). All records had the limitation of a relatively small sample size, with the largest cohort recruiting only 30 participants (28). The mean patient age ranged from 42 to 63 years, but only 3 authors reported the age. In all studies, 3-piece inflatable penile prostheses were implanted, and individuals were followed up for about 12 months. In studies reporting the plication technique performed, patients were treated with a longitudinal penile shaft incision without degloving $(26,27,29)$. A series of parallel, 2-0 non-absorbable polyester sutures (1-5 pairs) were used when simple plication without tunical incision was preferred. In one study, a subgroup of patients underwent the Yachia technique (28), if the penile curvature was discovered intraoperatively. In studies reporting relevant outcomes, the mean operative time was 83 minutes (88 minutes in the Yachia subgroup) $(27,28)$. In four trials, the mean preoperative penile curvature was about $40^{\circ}$ and in one about $90^{\circ}(16)$. On the other hand, the mean postoperative residual curvature was $\leq 15^{\circ}$ among all trials.

No studies objectively evaluated the postoperative penile length. A modified Patient Global Impression of Improvement (PGI-I) questionnaire was employed from two authors to evaluate the overall satisfaction and the penile length $(26,27)$. Three articles assessed the subjective perception of penile shortening that was reported from $50 \%$ to $80 \%$ of the participants. Regarding overall satisfaction, a generic improvement of the condition was reported in $83.3 \%$ to $90.9 \%$ of cases.

All investigators recorded potential complications and highlighted the safety of the surgical procedures examined. One article reported the presence of a non-functioning implant that was not replaced, the necessity of repairing a hernia in the space of Retzius and the need of adjacent tissue transfer for a partially buried penis (27).

All studies demonstrated that the plication techniques for residual curvature during PPI seem to be safe and effective in patients with mild to moderate penile curvature. No article reported a classic or modified Nesbit technique (48). Still, the plication technique has always the risk of damaging the implant during suturing. Therefore, in patients with known PD, the authors, in most cases, initially corrected the penile curvature and then proceeded to PPI. Furthermore, the identified studies may have included patients overtreated with plication, since in cases of penile curvature of around $30^{\circ}$, PPI alone or in combination with adjunctive maneuvers may adequately revert the curvature.

\section{Transcorporeal plaque incision techniques}

Three studies evaluated different transcorporeal plaque incision techniques combined with PPI to treat residual penile curvature (Table 2) (30-32). A total of 187 patients were included, with the study by Antonini et al. comprising the majority of them $n=145$ (31). In 2011, Shaeer introduced a transcorporal incision technique with the urethrotomy cold knife or the diathermy-knife of a resectoscope. A cystoscope was used to perform an optical corporotomy 
Table 1 Studies combining penile prosthesis implantation with additional penile plication

\begin{tabular}{|c|c|c|c|c|c|c|c|c|c|}
\hline Ref (year) & $\begin{array}{l}\text { Study period/ } \\
\text { origin/follow- } \\
\text { up }\end{array}$ & $\begin{array}{c}\text { Number } \\
\text { of patients } \\
\text { (mean age) }\end{array}$ & Surgical technique I & Implant type & $\begin{array}{l}\text { Pre-OP } \\
\text { curvature }\end{array}$ & $\begin{array}{l}\text { Post-OP } \\
\text { residual } \\
\text { curvature }\end{array}$ & $\begin{array}{l}\text { Post-OP } \\
\text { satisfaction } \\
\text { rate }\end{array}$ & $\begin{array}{l}\text { Post- } \\
\text { OP penile } \\
\text { length }\end{array}$ & Complications \\
\hline $\begin{array}{l}\text { Hudak et al. } \\
\text { (2013) }\end{array}$ & $\begin{array}{c}2007-2012 \\
\text { USA, } 14 \text { mo }\end{array}$ & $11(\mathrm{~N} / \mathrm{A})$ & $\begin{array}{l}\text { Simple plication } \\
\text { without tunical } \\
\text { incision; series } \\
\text { of 2-0 non- } \\
\text { absorbable } \\
\text { sutures; no } \\
\text { degloving }\end{array}$ & $\begin{array}{l}\text { Inflatable } \\
\text { 3-piece } \\
\text { penile } \\
\text { prothesis }\end{array}$ & $\begin{array}{c}41^{\circ} \\
\left(30^{\circ}-55^{\circ}\right)\end{array}$ & $4^{\circ}\left(0^{\circ}-10^{\circ}\right)$ & $90.9 \%$ & $\begin{array}{c}80 \% \\
\text { subjective } \\
\text { shorter } \\
\text { penis }\end{array}$ & $\begin{array}{c}\text { No major } \\
\text { complication }\end{array}$ \\
\hline $\begin{array}{l}\text { Tausch et al. } \\
(2015)\end{array}$ & $\begin{array}{l}2007-2014 \\
\text { USA, } 13 \text { mo }\end{array}$ & $30(N / A)$ & $\begin{array}{c}\text { Simple plication } \\
\text { without tunical } \\
\text { incision prior to } \\
\text { PPI: } 23 \\
\text { Yachia } \\
\text { corporoplasty after } \\
\text { PPI: } 7\end{array}$ & $\begin{array}{c}\text { Inflatable } \\
\text { 3-piece } \\
\text { penile } \\
\text { prothesis }\end{array}$ & $\begin{array}{l}\text { Plication: } \\
38^{\circ} \\
\left(20^{\circ}-80^{\circ}\right) \\
\text { Yachia: } \\
33^{\circ} \\
\left(25^{\circ}-45^{\circ}\right)\end{array}$ & $<10^{\circ}$ & $\begin{array}{c}\text { Plication: } \\
\text { 95\%; } \\
\text { Yachia: 86\% }\end{array}$ & $\mathrm{N} / \mathrm{A}$ & $\begin{array}{c}\text { No major } \\
\text { complication }\end{array}$ \\
\hline
\end{tabular}

IPP, inflatable penile prosthesis; mo, months; N/A, not available; OP, operative; PPI, penile prosthesis implantation; pt(s), patient(s); yrs, years.

of PD plaques from within the corpora cavernosa (30). Afterwards, Perito and Wilson developed the "scratch technique" for the correction of residual penile curvature during PPI. In this technique, a nasal speculum is inserted through the corporotomy openings to the site of the plaque. A longitudinal incision of the plaque from both cavernosal bodies is performed using a 12-blade scalpel (49). The results of the scratch technique were published by Antonini et al. in a large cohort of 145 patients (31). Recently, Shaeer et al. published a new transcorporeal technique for partial plaque excision during PPI using the stone punch forceps (32).

All studies included patients with moderate preoperative curvature ranging from $45^{\circ}$ to $70^{\circ}$. The mean patient age was 52 years and the follow-up ranged from 12 to 14 months. Only Antonini et al. reported a postoperative residual curvature of $>15^{\circ}$ in $6.2 \%$ of participants (31), while the other authors reported no residual curvature at one-year follow-up. The patients' satisfaction rate was very high in the studies of Shaeer et al. and moderate in the study of Antonini et al. (Table 2). Shaeer et al. reported no 
Table 2 Studies combining penile prosthesis implantation with additional transcorporeal plaque incision/excision

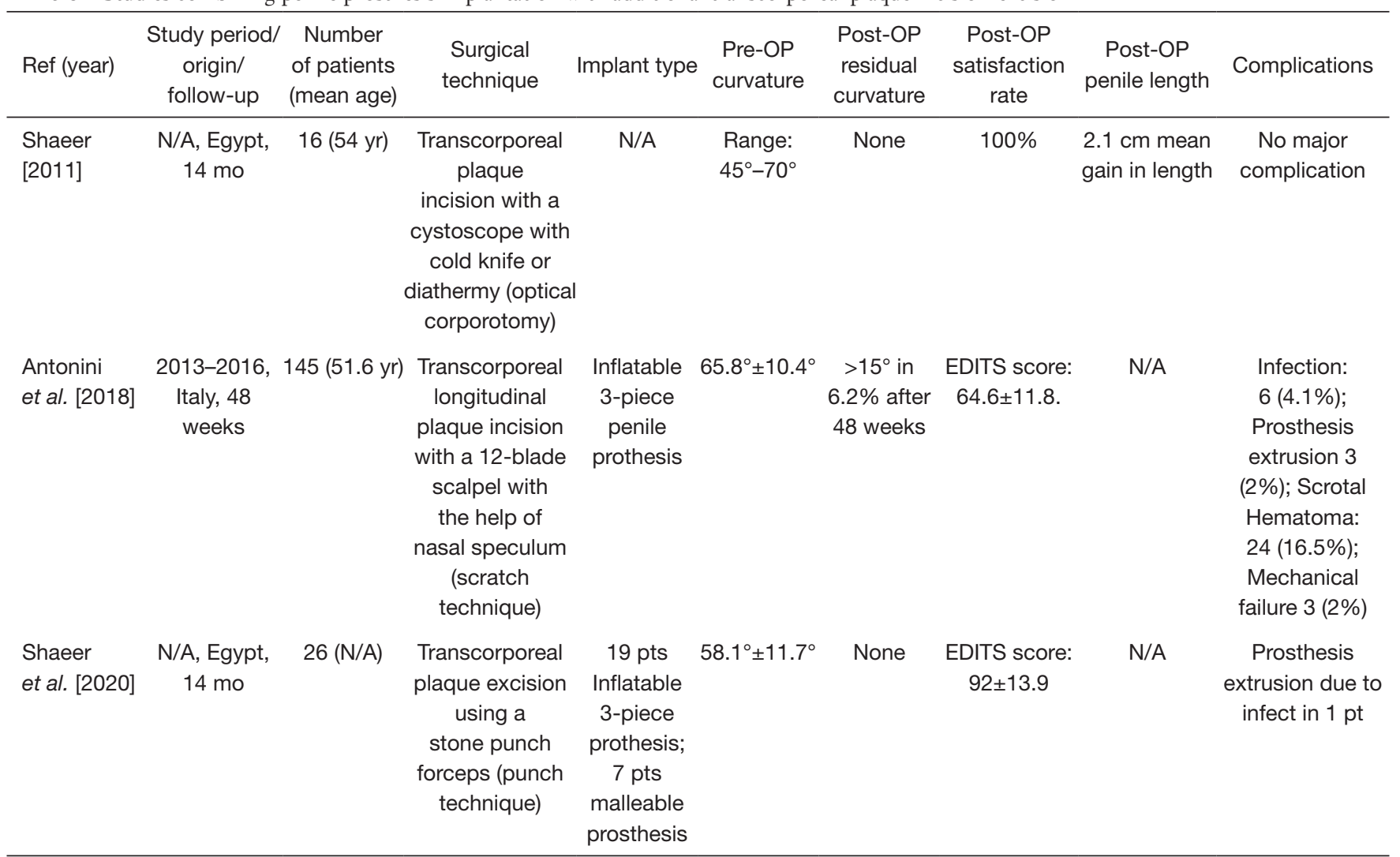

EDITS, erectile dysfunction index of treatment satisfaction; IPP, inflatable penile prosthesis; mo, months; N/A, not available; OP, operative; PPI, penile prosthesis implantation; pt(s), patient(s); yrs, years.

major complications in both of their studies, except from one prosthesis removal due to infection, which was later retreated with PPI without complications (32). On the other hand, Antonini et al. reported six postoperative infections, three prosthesis extrusions, three prosthesis malfunctions and 24 cases of scrotal haematoma (31).

All authors concluded that the transcorporeal plaque incision/excision techniques for residual curvature during PPI seem to be safe and effective in patients with moderate penile curvature. Since the plaque incision is performed before implant insertion, the major advantages of these techniques are the safety in terms of potential damage of the implant and the short operation time. Shaeer $e t a l$. demonstrated that the punch technique could significantly reduce the intervention time compared to grafting techniques (32).

\section{Plaque incision techniques}

A total of eight studies with 284 participants investigated the
PPI in combination with plaque incision(s) without grafting for the treatment of residual penile curvature (Table 3) (14,17-20,33-35). Three studies assessed the use of 3-piece inflatable penile prosthesis $(14,18,20)$, while one the use of malleable penile prosthesis (17). In three trials, both types of penile implants were evaluated (33-35). In most studies, the residual penile curvature was corrected with a transverse corporal incision(s) in the plaque or in the site of maximal penile curvature without grafting (14,17-20,33). The studies of Egydio and Kuehhas reported two modified sliding techniques without grafting for correction of penile curvature and restoration of penile length $(34,35)$. Preoperative mean penile curvature was reported in five studies and ranged from $45^{\circ}$ to $55^{\circ}(14,20,33-35)$. Most authors reported no postoperative residual curvature. Djordjevic et al. (33) recorded a mild residual curvature of $<20^{\circ}$ in three patients, while Montorsi et al. (20) reported a residual curvature in only one patient $(10 \%)$. The patient satisfaction rates were $>90 \%$ across studies and reached 
Table 3 Studies combining penile prosthesis implantation with additional plaque incision

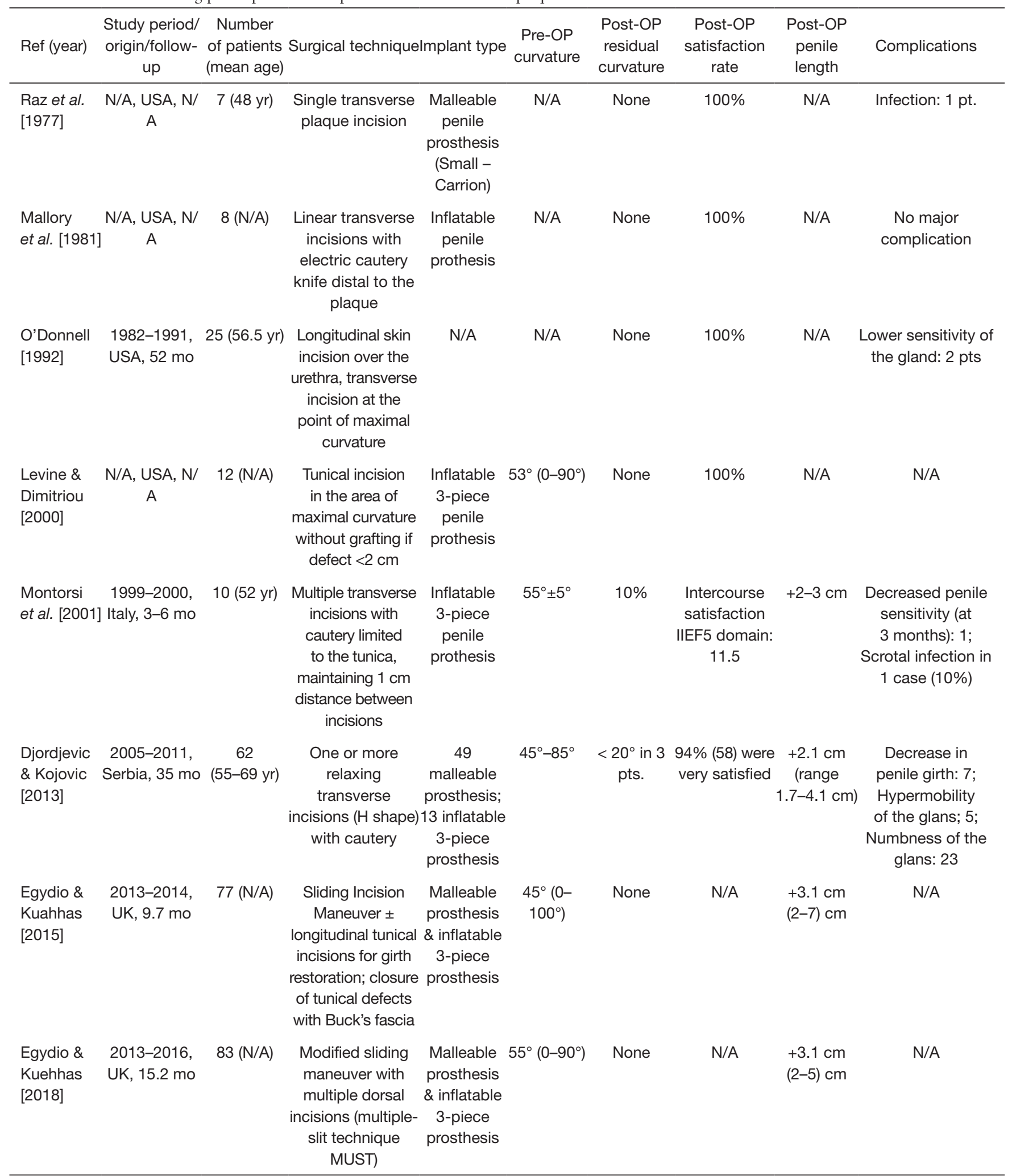

IIEF, international index of erectile function; IPP, inflatable penile prosthesis; mo, months; N/A, not available; OP, operative; pt(s), patient(s); yrs, years 
$100 \%$ in most of them. One study reported no intra- and post-operative complications (18). Conversely, four studies reported minor and major complications. In particular, numbness of the glans was described by O'Donnell in two of 25 patients (19) and by Djordjevic and Kojovic (33) in 23 of 62 patients. Infection was reported by Raz et al. (17) and Montorsi et al. (20) in one of seven and one of ten participants, respectively. Djordjevic and Kojovic described a decrease in penile circumference in 7 of 62 individuals and hypermobility of the glans in 5 of 62 (33). Of note, no mechanical failure or prosthesis extrusion was reported.

The techniques of corporal incision without grafting to restore residual penile curvature during PPI seem to be safe and effective in patients with moderate penile curvature. Levine and Dimitriou suggested that the use of grafting can be omitted if the tunical defect remains under $2 \mathrm{~cm}$ (14). The potential advantages of this technique are the high satisfaction rates and the avoidance of grafting. Furthermore, all incisional techniques and especially those using a sliding technique correct the penile length loss, which is secondary to PD. As disadvantages it may be considered the minor complications such as numbness of the glans due to the mobilization of the neurovascular bundle.

\section{Plaque incision/excision with additional grafting}

Nineteen studies investigated the results of PPI with additional tunical/plaque incision/excision and grafting of the defect for the correction of severe residual penile curvature (Table 4) (14,21-25,29,36-47). They included a total of 1,072 patients with a pooled mean age of 59.8 years (ranged from 51.2 to 67.2) and a pooled mean follow-up of 27 months (ranged from 6.6 to 45 months) (14,21-25,29, 36-47). Most studies assessed the use of inflatable 3-piece penile prosthesis $(14,21,29,38,42-45,47)$, while many of them included patients with both inflatable and malleable penile prosthesis $(23,24,36,37,39,41,46)$. Two studies evaluated the use of only malleable penile prosthesis $(22,40)$. Most trials performed a penoscrotal incision for the PPI and a separate subcoronal circular incision with degloving for the plaque incision/excision and grafting (14,21,38,41,43-46). Some studies, especially those that preferred a malleable prosthesis, performed only the subcoronal incision with degloving for both the PPI and grafting $(22-24,36,39,40,45,46)$. Two authors proposed a ventral longitudinal non-degloving incision from the frenulum to the scrotum $(29,42)$ and one an infrapubic approach $(25)$.
Most surgeons performed a single incision at the point of maximal curvature on the concave side or multiple relaxing incisions $(14,21-25,40,43,45,46)$. Some authors performed a circular incision of the tunica $(36,38,39)$, while others selected the sliding technique $(29,37,41,42)$.

A variety of grafting materials was used. In most trials, a pericardium allograft was preferred to cover the tunical defect $(21,23,24,39,40,42,45)$. Other grafting materials included porcine small intestinal submucosa $(37,41,43)$, InteXen collagen dermal matrix (36,38), PTFE-GoreTex (14), saphenous vein (22), and autologous rectus sheath (25). Of note, all the new and recently published studies assessed the use of collagen fleece to cover the defect (43-47). Additionally, one trial compared the effect of pericardium versus collagen fleece (45) and another porcine small intestinal submucosa versus collagen fleece (43). This highlights the increasing interest in the collagen fleece as a grafting material in PD surgery (50).

Among studies, the mean preoperative curvature was $67^{\circ}$ (ranged from $36.6^{\circ}$ to $77.7^{\circ}$ ) and the mean operative time ranged from 71.6 to 166 minutes (41-47). Interestingly, the mean operative time was shorter in studies using the collagen fleece as grafting material or a malleable penile prosthesis. Seven studies reported excellent results without any residual postoperative curvature of the penis. Still, in many studies, curvatures less than $10^{\circ}$ or $15^{\circ}$ were considered non-clinically significant and were not provided $(14,22-24,36,40,41,43,46)$. Patients' erectile function and satisfaction rate were very high in all studies, ranging from $80 \%$ to $100 \%$. Accordingly, postoperative residual curvatures were less than $20^{\circ}$ and occurred in about $15 \%$ of participants (Table 4).

An important advantage of grafting after plaque incision during PPI was the postoperative gain in penile length. Most studies measured pre- and postoperative penile length and reported a mean gain of 1.5 to $3.7 \mathrm{~cm}(22-24,36,38-42,46)$. Only minor complications were reported in most trials, which included numbness of the glans and minor hematomas. Postoperative infections, corpora erosions, or prosthesis malfunction were reported in similar rates compared to other techniques (Table 4).

Grafting techniques for the correction of severe residual penile curvature during PPI seem to be highly effective and safe. However, grafting techniques are more complex and require highly trained and experienced reconstructive surgeons. A major advantage, in addition to the small residual curvature rate, is the correction of penile shortening that is a major complain in patients with severe 


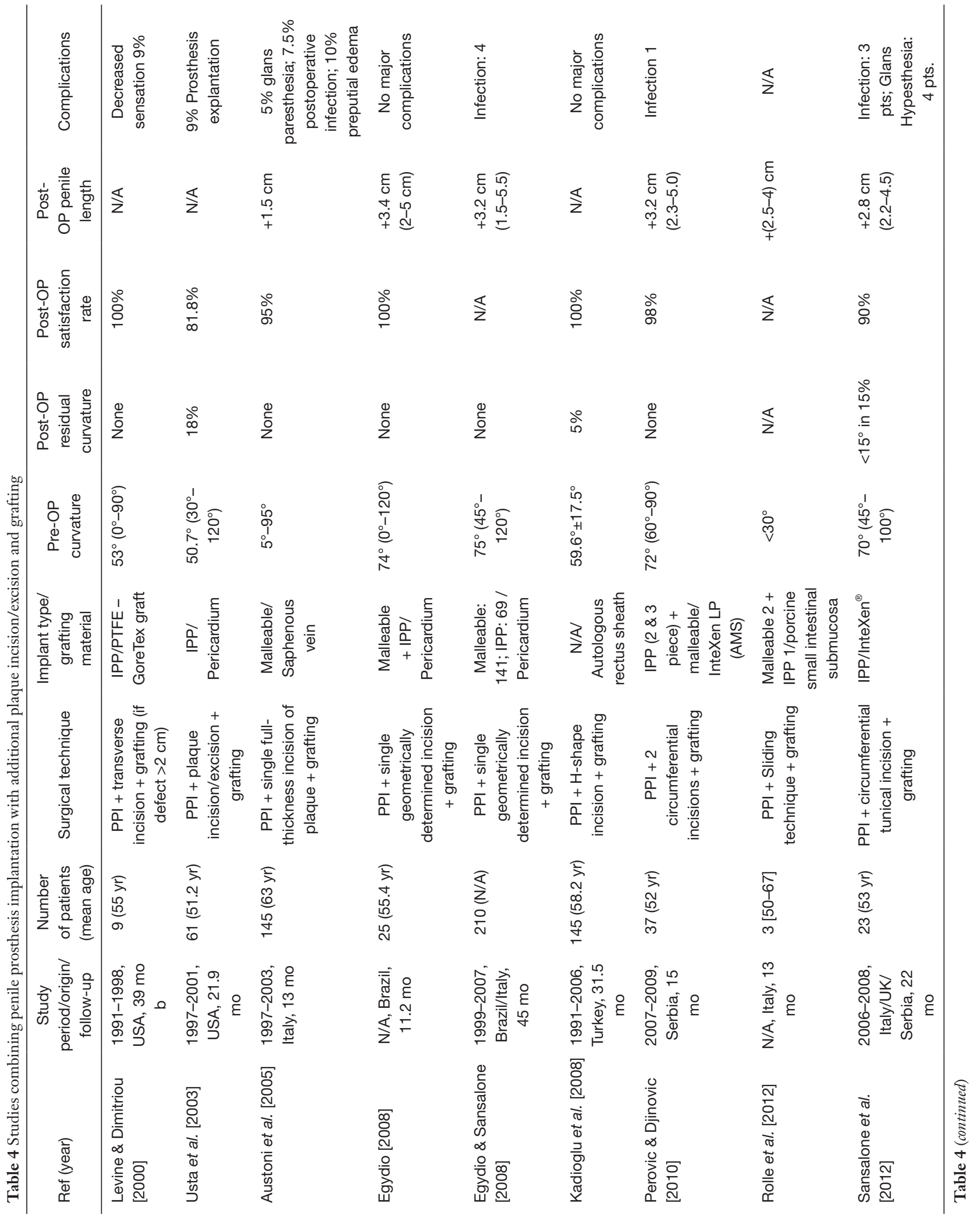




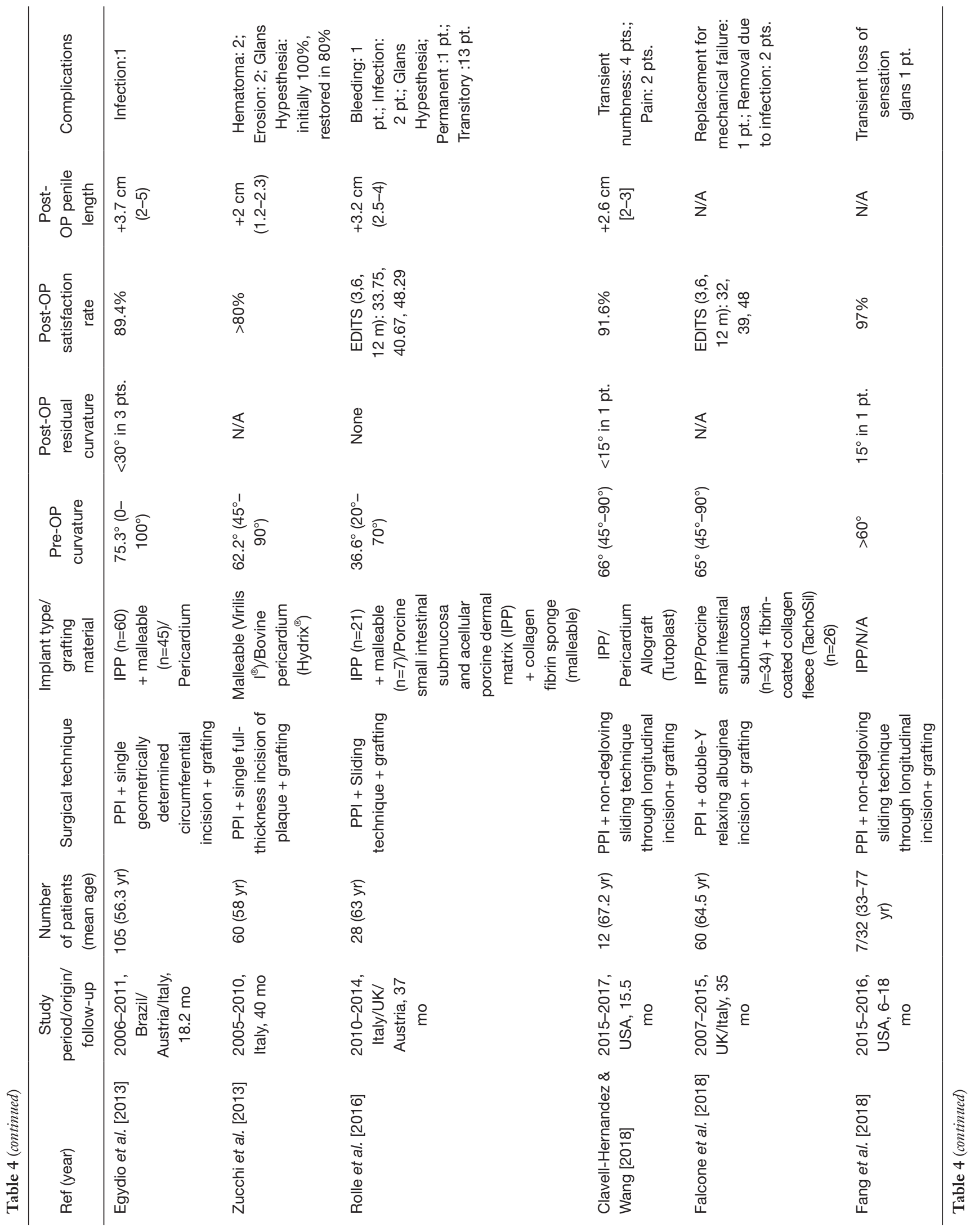




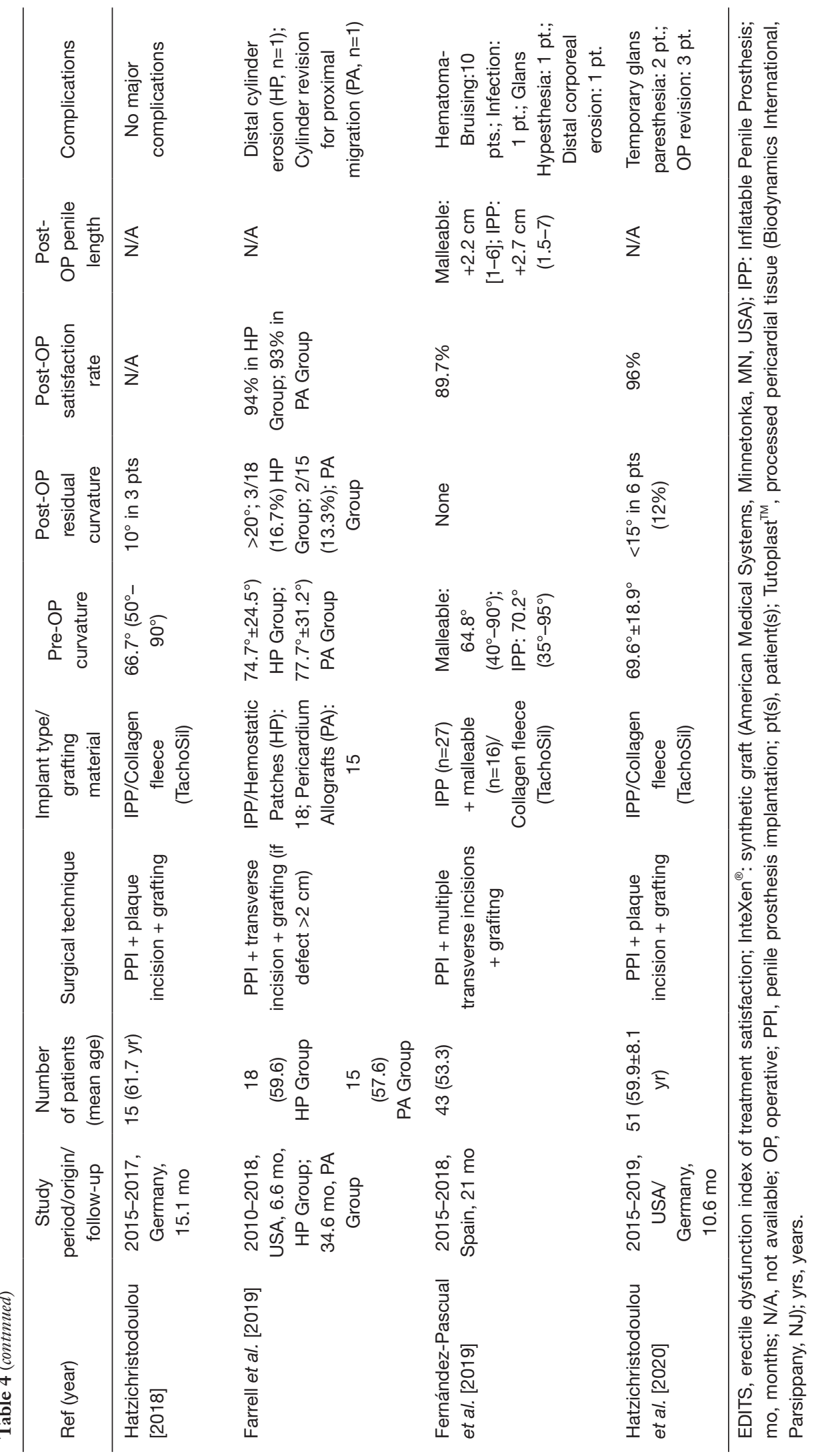


PD (51). Collagen fleece seems to be a very promising grafting material that reduces operating time and makes the grafting procedure simpler (50).

\section{Limitations of the study}

This comprehensive review has several limitations, which should be considered before generalizing the results and the conclusions should be adopted with caution. Overall, the limitations of this review reflect the limitation of lack of standardized outcomes in most of the included studies. Most of the studies did not include one or more of important outcomes measures (e.g., length, device malfunction, residual curvature) and most are not quantified with validated questionnaires or measurements. Furthermore, most of the studies addressed possible complication superficially and many studies did not included results regarding possible complications. The advantages and disadvantages of each technique as well as the potential complications display significant varieties. Therefore, they should be extensively discussed with the patient in order to define appropriate preoperative goals and expectations, aiming to achieve high satisfaction rates. Of interest, the surgeon's experience with a specific technique seems to both, define the postoperative outcomes and play an important role in the selection of treatment modalities. These limitations reduce the applicability of the findings to the surgeon who would like to know how these techniques truly compare to one another.

\section{Conclusions}

PPI combined with penile reconstruction for the correction of residual penile curvature in patients with $\mathrm{ED}$ and $\mathrm{PD}$ seems to be safe and effective. PPI alone or in combination with penile modelling seems to be the gold standard in penile curvatures of less than $30^{\circ}$. However, the latter is not reported in greater residual penile curvatures of more than $40^{\circ}$ or complex hourglass penile deformities. In this context, additional reconstruction techniques such as plication, transcorporeal plaque incision, simple tunical incisions and Plaque incision plus grafting are required. Of note, PPI with additional grafting seems also to be effective in patients with additional shortening of the penis. Due to the lack of large randomized controlled trials, no definite conclusions can be drawn regarding the superiority of one technique over the other. There is discordance and hence variation among the different outcomes reported from available studies. Further prospective comparative randomized controlled trials with standardized outcomes in patients treated with PPI due to severe ED and concomitant PD are needed.

\section{Acknowledgments}

Funding: None.

\section{Footnote}

Provenance and Peer Review: This article was commissioned by the Guest Editors (Francisco E. Martins and Tobias S. Köhler) for the series "Controversies and Considerations of Penile Surgery" published in Translational Andrology and Urology. The article has undergone external peer review.

Reporting Checklist: The authors have completed the Narrative Review Reporting Checklist. Available at: http:// dx.doi.org/10.21037/tau-20-1236

Conflicts of Interest: The authors have completed the ICMJE uniform disclosure form (available at http://dx.doi. org/10.21037/tau-20-1236). The series "Controversies and Considerations of Penile Surgery" was commissioned by the editorial office without any funding or sponsorship. The authors have no other conflicts of interest to declare.

Ethical Statement: The authors are accountable for all aspects of the work in ensuring that questions related to the accuracy or integrity of any part of the work are appropriately investigated and resolved.

Open Access Statement: This is an Open Access article distributed in accordance with the Creative Commons Attribution-NonCommercial-NoDerivs 4.0 International License (CC BY-NC-ND 4.0), which permits the noncommercial replication and distribution of the article with the strict proviso that no changes or edits are made and the original work is properly cited (including links to both the formal publication through the relevant DOI and the license). See: https://creativecommons.org/licenses/by-nc-nd/4.0/.

\section{References}

1. Salonia A, Bettocchi C, Carvalho J, et al. EAU Guidelines on sexual and reproductive health. Available online: https://uroweb.org/wp-content/uploads/EAU-Guidelineson-Sexual-and-Reproductive-Health-2020.pdf 
2. Chung E, Ralph D, Kagioglu A, Garaffa G, Shamsodini A, Bivalacqua T, Glina S, Hakim L, Sadeghi-Nejad H, Broderick G. Evidence-Based Management Guidelines on Peyronie's Disease. J Sex Med 2016;13:905-23.

3. Hatzichristodoulou G. Advances in the surgical treatment of Peyronie's disease. Curr Sex Health Rep 2016;8:186-92.

4. Hatzichristodoulou G, Tsambarlis P, Kübler H, et al. Peyronie's graft surgery-tips and tricks from the masters in andrologic surgery. Transl Androl Urol 2017;6:645-56.

5. Sokolakis I, Hatzichristodoulou G. Current trends in the surgical treatment of congenital penile curvature. Int J Impot Res 2020;32:64-74.

6. Hatzichristodoulou G. Grafting techniques for Peyronie's disease. Transl Androl Urol 2016;5:334-41.

7. Wilson SK, Delk JR 2nd. A new treatment for Peyronie's disease: modeling the penis over an inflatable penile prosthesis. J Urol 1994;152:1121-3.

8. Eigner EB, Kabalin JN, Kessler R. Penile implants in the treatment of Peyronie's disease. J Urol 1991;145:69-71; discussion -2 .

9. Wilson SK, Cleves MA, Delk JR 2nd. Long-term followup of treatment for Peyronie's disease: modeling the penis over an inflatable penile prosthesis. J Urol 2001;165:825-9.

10. Wilson SK, Simhan J. Is modeling an inflatable penile prosthesis obsolete for patients with Peyronie's disease? Int J Impot Res 2020;32:267-73.

11. Moncada I, Krishnappa P, Ascencios J, et al. Home modeling after penile prosthesis implantation in the management of residual curvature in Peyronie's disease. Int J Impot Res 2020. doi: http://dx.doi.org/10.1038/ s41443-020-0325-6.

12. Lucas JW, Gross MS, Barlotta RM, et al. Optimal Modeling: an Updated Method for Safely and Effectively Eliminating Curvature During Penile Prosthesis Implantation. Urology 2020;146:133-9.

13. Whelan P, Levine LA. Additional procedures performed at time of penile prosthesis implantation: a review of current literature. Int J Impot Res 2020;32:89-98.

14. Levine LA, Dimitriou RJ. A surgical algorithm for penile prosthesis placement in men with erectile failure and Peyronie's disease. Int J Impot Res 2000;12:147-51.

15. Mulhall J, Anderson M, Parker M. A surgical algorithm for men with combined Peyronie's disease and erectile dysfunction: functional and satisfaction outcomes. J Sex Med 2005;2:132-8.

16. Rahman NU, Carrion RE, Bochinski D, et al. Combined penile plication surgery and insertion of penile prosthesis for severe penile curvature and erectile dysfunction. J Urol
2004;171:2346-9.

17. Raz S, Dekernion JB, Kaufman JJ. Surgical treatment of Peyronie's disease: a new approach. J Urol 1977;117:598-601.

18. Malloy TR, Wein AJ, Carpiniello VL. Advanced peyronie's disease treated with the inflatable penile prosthesis. J Urol 1981;125:327-8.

19. O'Donnell PD. Results of surgical management of Peyronie's disease. J Urol 1992;148:1184-7.

20. Montorsi F, Salonia A, Maga T, et al. Reconfiguration of the severely fibrotic penis with a penile implant. J Urol 2001;166:1782-6.

21. Usta MF, Bivalacqua TJ, Sanabria J, et al. Patient and partner satisfaction and long-term results after surgical treatment for Peyronie's disease. Urology 2003;62:105-9.

22. Austoni E, Colombo F, Romano AL, et al. Soft prosthesis implant and relaxing albugineal incision with saphenous grafting for surgical therapy of Peyronie's disease: a 5-year experience and long-term follow-up on 145 operated patients. Eur Urol 2005;47:223-9; discussion 9.

23. Egydio PH. Surgical treatment of Peyronie's disease: choosing the best approach to improve patient satisfaction. Asian J Androl 2008;10:158-66.

24. Egydio PH, Sansalone S. Peyronie's reconstruction for maximum length and girth gain: geometrical principles. Adv Urol 2008;2008:205739.

25. Kadioglu A, Sanli O, Akman T, et al. Surgical treatment of Peyronie's disease: a single center experience with 145 patients. Eur Urol 2008;53:432-9.

26. Hudak SJ, Morey AF, Adibi M, et al. Favorable patient reported outcomes after penile plication for wide array of peyronie disease abnormalities. J Urol 2013;189:1019-24.

27. Chung PH, Scott JF, Morey AF. High patient satisfaction of inflatable penile prosthesis insertion with synchronous penile plication for erectile dysfunction and Peyronie's disease. J Sex Med 2014;11:1593-8.

28. Tausch TJ, Chung PH, Siegel JA, et al. Intraoperative Decision-making for Precise Penile Straightening During Inflatable Penile Prosthesis Surgery. Urology 2015;86:1048-52.

29. Fang A, Wang R. Nondegloving technique for Peyronie's disease with penile prosthesis implantation and double dorsal-ventral patch graft. Asian J Androl 2018;20:90-2.

30. Shaeer O. Trans-corporal incision of Peyronie's plaques. J Sex Med 2011;8:589-93.

31. Antonini G, De Berardinis E, Del Giudice F, et al. Inflatable Penile Prosthesis Placement, Scratch Technique and Postoperative Vacuum Therapy as a Combined 
Approach to Definitive Treatment of Peyronie's Disease. J Urol 2018;200:642-7.

32. Shaeer O, Soliman Abdelrahman IF, Mansour M, et al. Shaeer's Punch Technique: Transcorporeal Peyronie's Plaque Surgery and Penile Prosthesis Implantation. J Sex Med 2020;17:1395-9.

33. Djordjevic ML, Kojovic V. Penile prosthesis implantation and tunica albuginea incision without grafting in the treatment of Peyronie's disease with erectile dysfunction. Asian J Androl 2013;15:391-4.

34. Egydio PH, Kuehhas FE. Penile lengthening and widening without grafting according to a modified 'sliding' technique. BJU Int 2015;116:965-72.

35. Egydio PH, Kuehhas FE. The Multiple-Slit Technique (MUST) for Penile Length and Girth Restoration. J Sex Med 2018;15:261-9.

36. Perovic SV, Djinovic RP. Current surgical management of severe peyronie's disease. Arch Esp Urol 2010;63:755-70.

37. Rolle L, Ceruti C, Timpano M, et al. A new, innovative, lengthening surgical procedure for Peyronie's disease by penile prosthesis implantation with double dorsalventral patch graft: the "sliding technique". J Sex Med 2012;9:2389-95.

38. Sansalone S, Garaffa G, Djinovic R, et al. Simultaneous penile lengthening and penile prosthesis implantation in patients with Peyronie's disease, refractory erectile dysfunction, and severe penile shortening. J Sex Med 2012;9:316-21.

39. Egydio PH, Kuehhas FE, Sansalone S. Penile length and girth restoration in severe Peyronie's disease using circular and longitudinal grafting. BJU Int 2013;111:E213-9.

40. Zucchi A, Silvani M, Pecoraro S. Corporoplasty with small soft axial prostheses (VIRILIS I(R)) and bovine pericardial graft (HYDRIX(R)) in Peyronie's disease. Asian J Androl 2013;15:275-9.

41. Rolle L, Falcone M, Ceruti C, et al. A prospective multicentric international study on the surgical outcomes and patients' satisfaction rates of the 'sliding' technique for end-stage Peyronie's disease with severe shortening of the penis and erectile dysfunction. BJU Int 2016;117:814-20.

42. Clavell-Hernandez J, Wang R. Penile Size Restoration With Nondegloving Approach for Peyronie's Disease: Initial Experience. J Sex Med 2018;15:1506-13.

43. Falcone M, Preto M, Ceruti C, et al. A Comparative Study Between 2 Different Grafts Used as Patches After Plaque
Incision and Inflatable Penile Prosthesis Implantation for End-Stage Peyronie's Disease. J Sex Med 2018;15:848-52.

44. Hatzichristodoulou G. The PICS Technique: A Novel Approach for Residual Curvature Correction During Penile Prosthesis Implantation in Patients With Severe Peyronie's Disease Using the Collagen Fleece TachoSil. J Sex Med 2018;15:416-21.

45. Farrell MR, Abdelsayed GA, Ziegelmann MJ, et al. A Comparison of Hemostatic Patches Versus Pericardium Allograft for the Treatment of Complex Peyronie's Disease With Penile Prosthesis and Plaque Incision. Urology 2019;129:113-8.

46. Fernandez-Pascual E, Gonzalez-Garcia FJ, RodriguezMonsalve M, et al. Surgical Technique for Complex Cases of Peyronie's Disease With Implantation of Penile Prosthesis, Multiple Corporeal Incisions, and Grafting With Collagen Fleece. J Sex Med 2019;16:323-32.

47. Hatzichristodoulou G, Yang DY, Ring JD, et al. Multicenter Experience Using Collagen Fleece for Plaque Incision With Grafting to Correct Residual Curvature at the Time of Inflatable Penile Prosthesis Placement in Patients With Peyronie's Disease. J Sex Med 2020;17:1168-74.

48. Sokolakis I, Schonbauer P, Mykoniatis I, et al. Long-Term Results after Surgical Treatment of Congenital Penile Curvature Using a Modified Nesbit Technique. World J Mens Health 2020;38:564-72.

49. Perito P, Wilson S. The Peyronie's plaque "scratch": an adjunct to modeling. J Sex Med 2013;10:1194-7.

50. Hatzichristodoulou G. Evolution of the surgical sealing patch TachoSil(®) in Peyronie's disease reconstructive surgery: technique and contemporary literature review. World J Urol 2020;38:315-21.

51. Chung E. Penile Reconstructive Surgery in Peyronie Disease: Challenges in Restoring Normal Penis Size, Shape, and Function. World J Mens Health 2020;38:1-8.

Cite this article as: Sokolakis I, Pyrgidis N, Mykoniatis I, Dimitriadis F, Hatzichristodoulou G. A comprehensive narrative review of residual curvature correction during penile prosthesis implantation in patients with severe erectile dysfunction and concomitant Peyronie's disease. Transl Androl Urol 2021;10(6):2669-2681. doi: 10.21037/tau-20-1236 